\title{
The Perception of English Stress by North Sinai Bedouins
}

Alaa Yousef Eshak YousefEl-Daly

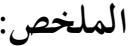

إن الهدف الاساسى من هذه الدراسة هو دراسة تأثير اللهجة العربية البدوية على انتاج

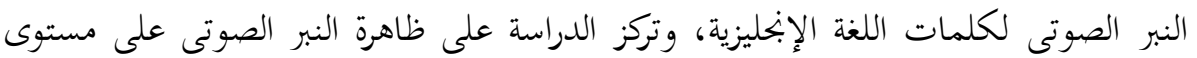

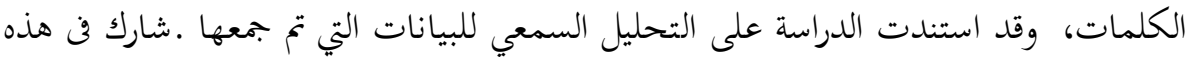

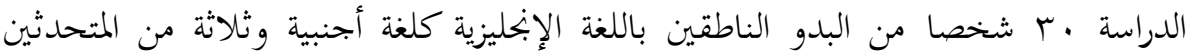

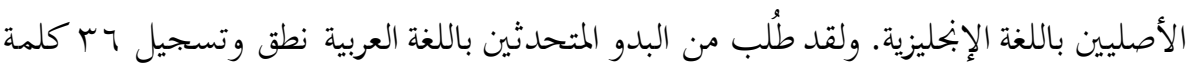

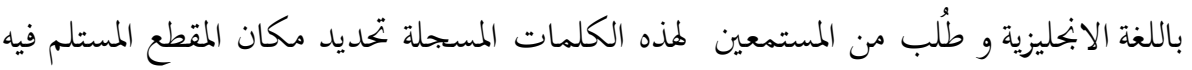

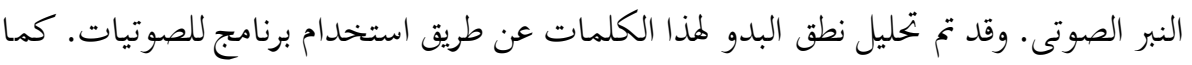

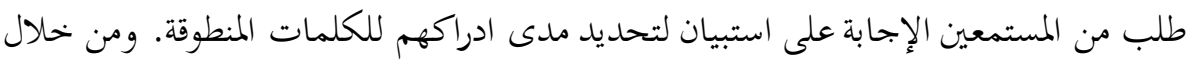

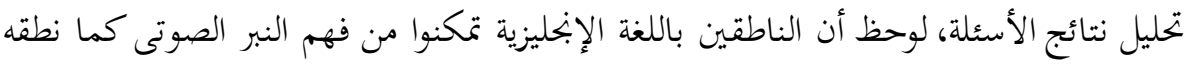



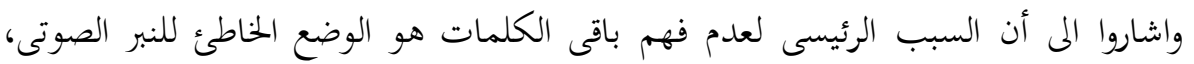

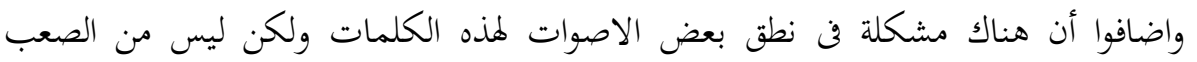

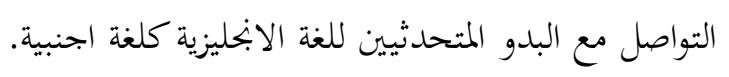

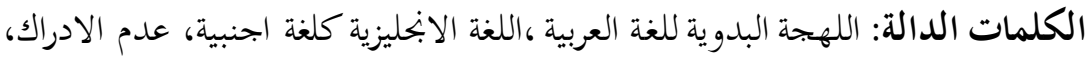
النبر الصوتى ،خطأ النطق، وضع النبر الصوتى ،البروز.
\end{abstract}

\section{Abstract}

The main aim of this thesis is to investigate the effect of Bedouin dialect of Arabic on producing English word stress and how it can influence the comprehensibility of the perceived words. The study investigates the phenomenon of 
English word stress based on an auditory analysis. The participants of the study are 30 Bedouin speakers of English as a foreign language and three English native speakers. Bedouin speakers are asked to produce 36 words which consist of two syllables, three syllables, four syllables and five syllables. Their production of the words is recorded, then English native speakers are asked to listen to the recorded words and mark the perceived syllable and their comprehensibility of each word. Finally, the raters are asked to answer a questionnaire to measure their comprehensibility of all that they listen to. The results show that English native speakers perceive the primary stress as it is produced by the Bedouins and can comprehend more than half of the words produced by Bedouin speakers of EFL. English listeners explain that the misplacement of stress can cause incomprehensibility and it is somewhat hard to communicate with them. Furthermore, Bedouin speakers of EFL pronounce English words and produce stress influenced by their Bedouin dialect of Arabic.

\section{Introduction}

The main aim of this thesis is to investigate the effect of Bedouin dialect of Arabic on producing English word stress and how it can influence the comprehensibility of the perceived words. The study investigates the phenomenon of English word stress and how it changes in a word as a result of making it more or less prominent by varying the information structure from an auditory point of view. The target dialect that will be investigated in the current study is Bedouin 
dialect of Arabic in North Sinai. In this regard, the study presents the phonological effects of word stress position such as word length, syllable structure, and number of syllables. It concentrates on the importance of stress placement and how the incorrect placement of stress affects the comprehensibility and intelligibility.

\section{Statement of the Problem}

The present study is an attempt to find out how NSBSs of EFL produce and place stress on English words and to detect how their production can influence the comprehensibility of the perceived syllable by English native speakers. On the other hand, it utilizes a socio-phonetics approach to study the effect of Bedouin dialect of Arabic on producing English word stress. The study suggests that NSB speakers of EFL show interesting differences in producing English words and that may lead to incomprehensibility.

\section{Aims of the Study}

The current study mainly aims at investigating the effect of the first language (Bedouin dialect of Arabic) on the production of the second language (English) as a foreign language $(\mathrm{EFL})$, discovering patterns of errors in the production of English word stress among non-native speakers of North Sinai whose first language is Bedouin dialect of Arabic and whether or not these errors affect the comprehensibility of English words as produced by NSB speakers of Arabic, presenting the stress characteristics of Bedouin dialect of Arabic in North Sinai that is spoken there, 
examining the differences between the patterns of stress in English and the patterns of stress in Bedouin dialect of Arabic in North Sinai and accurately describing the causes or the reasons for errors made by Bedouin speakers of English as a foreign language, especially word stress errors.

\section{Study Questions}

The current study attempts to answer the following questions:

1. To what extent does the regional dialect of Egyptian Arabic 'Bedouin dialect of Arabic' affect stress placement in case they speak English as a foreign language?

2. How does stress misplacement as produced by north Sinai Bedouin speakers of Arabic affect perception or understanding of the language they produce?

3. What are the stress rules of north Sinai Bedouin dialect of Arabic that affect Bedouin speakers' production of English as a foreign language?

In order to find answers to these questions, a combination of quantitative and qualitative analysis will be utilized for the study.

\section{Hypothesis}


The study hypothesized that BSs of EFL make mistakes when placing the primary stress in English words influenced by their stress rules of Bedouin dialect of Arabic. Furthermore, it is hypothesized that English native speakers can comprehend and interact with the BSs of EFL without any difficulty.

\section{Data Collection}

The target dialect that is investigated in the current study is Bedouin dialect of Arabic in North Sinai area. The words that have been selected for this study are 36 polysyllabic words. These words contain two syllables, three syllables, four syllables, and five syllables. The data is collected from 30 adult male students at North Sinai University, AlArish branch, in different faculties such as Dentistry, Pharmacy and Engineering. Ten Bedouin participants study at the faculty of Dentistry, ten of them study at the faculty of Pharmacy and at the others study at the faculty of Engineering. The Bedouins who participated are from different tribes such as Tarabin, Biliy, Dawagrah, Biyyadiyyah, Ayaydah, El Rmelat, Sawarkah, Agaylah, Riyashat, Malalhah, Gatawiyyah, and Ayaida. Three English native speakers participated to complete the data. They are aged between 40 and 60 years and they are two females and a male.

\section{Procedures}

Bedouin speakers of English as a foreign language are asked to pronounce the targeted words designed by the 
researcher. The Bedouin's production of English words is recorded and the listeners are asked to listen to these recordings. Then the listeners are asked to write the words which they listen to and mark the perceived syllable. Finally, English native participants are asked to answer some questions to evaluate their comprehensibility of what is said by Bedouin speakers of English as a foreign language.

Follow up questions:

Firstly, English native participants are asked to rate how well they can hear the BSs of EFL or rank their comprehensibility of what was said by using Likert scale.

a) Comprehend nothing.

b) Comprehend some, but not much.

c) Comprehend about half.

d) Comprehend more than half.

e) Comprehend all of what was said.

Then the participants are asked to answer the following questions:

1. Why cannot you comprehend the Bedouin speakers of English as a foreign language? Choose the reason according to your point of view from the following points.

a) The acoustic/sound quality of the speaker.

b) The words he spoke and the way he spoke them.

c) The placement of the stress.

d) The dialect or accent of the speaker. 
2. How easy do you find it to comprehend the Bedouin speakers?
a) Easy
b) Moderate
c) Somewhat hard
d) Hard
e) Extremely hard

3. How easy do you think it would be for you to communicate with the Bedouin speakers?
a) Easy
b) Moderate
c) Somewhat hard
d) Hard
e) Extremely hard

\section{Theoretical frame work}

Patterns of Word Stress in Bedouin Dialect of

\section{Arabic}

- Bedouins of Arabic tend to keep the length of long vowels in unstressed positions.

- Resyllabication of $\mathrm{C}_{1} \mathrm{C}_{2} \mathrm{Cv}$ sequences do not occur in Bedouin dialect of Arabic such as: a piece of paper [waragah].

- In Bedouin dialect of Arabic, stress is based on the criterion of quantity. For example; (i) vowels of heavy sequence (CVVC and CVCC) are stressed, (ii) The 
vowel of the first heavy syllable from the right is stressed such as she was married [atg'awwazat].

- In words which have no heavy sequences, Bedouins stress the vowel in the second syllable from the left, or the first syllable from the left. So, the stress-type $\mathrm{CaC}^{\prime} \mathrm{aCv}$ shifts to be stressed as $\mathrm{C}^{\prime} \mathrm{aCaCv}$.

- Stress in the type which has no heavy sequences such as the pattern $\mathrm{CaCaCv}$ is stressed as $\mathrm{C}^{\prime} \mathrm{aCaCv}$ or $\mathrm{CaC}^{\prime} \mathrm{aCv}$. For example: sheep may be stressed as [g'anam] or [gan'am].

- Stress in the type of $\mathrm{CaCaCaCv}$ tends to be on the vowel of the second syllable $\mathrm{CaC}^{\prime} \mathrm{aCaCv}$ such as: his net [Jabakatih].

\section{English Word Stress}

According to Field (2004), Ladefoged (1993), and Roach (2000, p. 85-6), English word stress has two aspects which are perception and production. The production of stress depends on the speaker's use of more muscular energy. In other words, the stressed syllable of a polysyllabic word is pronounced longer in duration, louder and higher in pitch than the unstressed syllables. The perception of stress depends on how prominent the syllable is. Roach, Ladefoged, and Field explain that "the perception of word stress is the recognition of the stressed syllable of a word". Thus, speakers of EFL will not be able to produce sounds successfully if they cannot perceive the stress correctly. 
Roach (2000, p. 85-6) and McMahon (2002, p. 129) illustrate four degrees of stress: primary, secondary, tertiary, and weak stress. These four degrees are known with different terms according to Sweet (1890): emphatic, strong, medium, and weak. In other words, they can be called strong, halfstrong, half-weak, and weak. hence, Ladefoged (1993) and Field (2004) indicate that stress can be produced by higher pitch as well as longer duration and greater intensity. For example, when we say the word sugar, the first syllable will be higher in pitch, longer in vowel duration, and louder than the second syllable. In contrast, Roach (2009, p.119) illustrates three possibilities or degrees of stress within a word: primary stress, and it is "characterized by prominence, and basically, by a rise-fall tone". Secondary stress, Roach calls it "a lexical stress" and it is "weaker than the primary stress but it is stronger than that of the unstressed syllables". The unstressed syllables which regarded as "being the absence of any recognizable amount of prominence". The unstressed syllables normally contain the short-closed vowels /I/, /e/, /u/ and the schwa $/ \mathrm{o} /$.

\section{Literature Review}

Helal (2014) investigates the problems native speakers of Arabic, particularly Egyptian Arabic (EA), face in learning two-to-five syllable words. He focuses on examining compound words in English regarding stress assignment. The study attempts to identify the reasons of the difficulties that Egyptian Arab learners face in determining the position of 
stress. Furthermore, he aims to suggest some corrective steps for students to avoid these difficulties in the future. Hence, these steps will help them to improve their performance in this field and enhance the process of learning. The study depends on metrical theory and is based on four tests. The first one is written test and the second is audio-recorded. These tests are part of a course entitled English Phonetics and Phonology and are initial tests at the beginning of the academic term. The other two tests are at the end of the term. The words used in the testing represent either a match or a mismatch of the metrical parameter's settings and stress placement rules for Egyptian Arabic and English. The findings show that the students respond to the weight of the syllable, ignoring the stress rules of English language and hence, they transfer the stress pattern of their language L1 to target language L2. Therefore, the students wrongly place stress on the second syllable instead of the first one. Word length is associated with low performance of students. While, in compound words which consist only of two syllables, the phonological structures of stressed syllables which are different from that of EA are among the main reasons for incorrect stress placement on the part of the students 
Data Analysis

\begin{tabular}{|c|c|c|}
\hline The word & ledouin B & edouin B \\
\hline 1.current & & \\
\hline 2. career & & \\
\hline
\end{tabular}

Table 1

The overall results of the production of words by30 BSs of EFL

\begin{tabular}{|c|c|c|c|}
\hline Word group & No. or words & Correct production by BSs & Tincorrect production by $\mathrm{BS}$ \\
\hline Two syllables & & 165 & 45 \\
\hline Two syllables & & 144 & 60 \\
\hline Three syllables & 8 & 172 & 68 \\
\hline Tour syntattes & & 159 & $T$ \\
\hline Tive sylavius & & & \\
\hline Total & & 808 & 272 \\
\hline Percentages & & $74.81 \%$ & $20.1 \%$ \\
\hline
\end{tabular}

Table 2

The overall results of the ENSs perception of the produced words by BSs 


\begin{tabular}{|c|c|c|c|c|c|c|c|}
\hline \multirow{2}{*}{ Word group } & \multirow[t]{2}{*}{$\begin{array}{l}\text { No. of } \\
\text { words }\end{array}$} & \multicolumn{3}{|c|}{$\begin{array}{r}\text { Correct perception of the } \\
\text { raters }\end{array}$} & \multicolumn{3}{|c|}{$\begin{array}{r}\text { Incorrect perception of the } \\
\text { raters }\end{array}$} \\
\hline & & $\overline{R 1}$ & $\mathbf{R 2}$ & R3 & R1 & $\mathbf{R 2}$ & R3 \\
\hline Two syllables & 7 & 168 & 164 & 167 & 42 & 46 & 43 \\
\hline Two-syllables & 7 & 144 & 137 & 141 & 66 & 73 & 69 \\
\hline Three-syllables & 8 & 173 & 166 & 170 & 67 & 74 & 70 \\
\hline Four-syllables & 7 & 157 & 153 & 153 & 53 & 57 & 57 \\
\hline Five-syllables & 7 & 168 & 167 & 166 & 42 & 43 & 44 \\
\hline Total & & 810 & 787 & 797 & 270 & 293 & 283 \\
\hline Percentages & & $75 \%$ & $72.87 \%$ & $73.79 \%$ & $25 \%$ & $27.12 \%$ & $26.20 \%$ \\
\hline
\end{tabular}

\section{Table 3}

As shown in table 3 , the first rater perceives correctly (75\%) of the words and (25\%) incorrectly. The second rater perceives correctly (72.87\%) of the words and (27.12\%) incorrectly. The third rater perceives correctly $(73.79 \%)$ of the words and (26.20\%) incorrectly. Hence, there is a high inter-rater reliability between the raters.

The overall results of the comprehensibility of the

\section{ENSs}

\begin{tabular}{|l|c|c|c|}
\hline Words & Rater 1 & Rater 2 & Rater 3 \\
\hline 36 words & 697 & 700 & 713 \\
\hline Percentages & $\mathbf{6 4 . 5 3 \%}$ & $\mathbf{6 4 . 8 1 \%}$ & $\mathbf{6 6 . 0 1 \%}$ \\
\hline
\end{tabular}

\section{Table 4}

With regard to the comprehensibility of the three raters, the first rater can comprehend all the words (64.53\%), the second rater (64.81\%) and the third rater (66.01\%). 


\section{The listeners' Responses of the Questionnaire}

This section presents the results of the questionnaire which is answered and completed by the three English native raters. According to the first question results 'could you rate your comprehensibility of what is said?'. It can be noted that all the listeners are able to comprehend most of the words which they listen to. The response rate is $(100 \%)$ of the listeners can comprehend more than half. None of them can get all the words, while ( $0 \%$ ) could grasp nothing. According to the results the second question, none of the listeners $(0 \%)$ reported that they cannot understand the BSs of EFL because of the acoustic/sound quality or the dialect or the accent of the speakers. The listeners cannot grasp the words (100\%) because of the placement of stress. In addition, one of the rater comments that the words that were spoken by the Bedouins and the way they spoke might be considered as a reason for the incomprehensibility. In response to the third question, table 7 shows that all the listeners find it moderate $(100 \%)$ to understand the BSs of EFL. On the other hand, $(0 \%)$ of the listeners find it easy or hard or extremely hard to understand them. With regard to the fourth question, none of the listeners $(0 \%)$ reported that it is easy to communicate with the BSs, while (66.66\%) thought that it would be somewhat hard. (33.33\%) of the listeners thought it is moderate and $(0 \%)$ thought it is mostly hard or extremely hard to communicate with the BSs. 


\section{The Findings}

With regard to the analysis and statistical results, it can be revealed that BSs of EFL produce the primary stress correctly (74.81\%) and produce it incorrectly $25.1 \%$ ) of the 36 words. The study shows that BSs of EFL produce stress incorrectly because of the influence of Bedouin dialect of Arabic. The results also show that BSs of EFL, in general, find it easy to produce stress in two-syllable words which have stress in the penultimate syllable (e.g. current) and with words which have stress on the final syllable (e.g. prefer). Furthermore, they find difficulty in stressing antepenultimate syllables (e.g. certainly), and preantepenultimate syllables (e.g. controversy).

Therefore, the study shows that the overall response to the comprehensibility is that English native speakers (the raters) can perceive more than half of the words which are pronounced by Bedouin speakers of EFL but not all what they say while the perception of the words. With regard to the perception, the study also reveals that the first rater perceives the words correctly (75\%) and (25\%) incorrectly. The second rater perceives the words correctly (72.87\%) and $(27.12 \%)$ incorrectly. The third rater perceives the words correctly (73.79\%) and incorrectly (26.20\%). Hence, there is a high inter-rater reliability between the raters in the perception of the 36 words by BSs of EFL. The results confirm that the raters are able to judge in perceiving the 
syllables by the BSs of EFL and there is a high agreement rate between them.

Related to the production and the perception of the words, BSs of EFL produce the primary stress correctly (74.81\%) and the raters perceive it correctly (75\%, 72.87\% and $73.79 \%$ ). In contrast, BSs of EFL produce the primary stress incorrectly (25.1\%) and the raters perceive it incorrectly (25\%, 27.12\% and 26.20\%). Hence, the inter-rater reliability between the first and the second raters indicates that there is a homogeneity between them and their judgment is very related to each other.

With regard to the comprehensibility of the words, the first rater can comprehend all the words which are produced by BSs of EFL (64.53\%), the second rater (64.81\%) and the third rater (66.01\%). In relation to the questionnaire, the three raters mention that they can comprehend more than half of the words and their answers are relevant to the total percentages of the perception of the 36 words. Hence, these percentages of the rater's comprehensibility of the words prove that they can understand more than half of the words. In addition, the raters find it moderate to understand the BSs of EFL. This gain does not support the hypothesis of the study and indicates that the errors in placing the primary stress correctly on words can cause incomprehensibility.

\section{Answers of the Research Questions}

In light of the study questions, the first question, (To what extent does the regional dialect of Egyptian Arabic 
'Bedouin dialect of Arabic' affect stress placement in case they speak EFL?), is considered in as an open question about the influence of mother tongue on producing the second language. Bedouin dialect of Arabic has patterns of stress which differ from English language. BSs of EFL use their stress rules when producing English word stress. Bedouin speakers of Arabic usually form stress according to the criterion of quantity and, in the absence of quantity, they place stress based on the number of syllables because Bedouin dialect of Arabic is a "syllable-timed" language.

Related to the second question 'How does stress misplacement as produced by NSB speakers of Arabic affect perception or understanding of the language they produce?', the study shows that ENSs can comprehend more than half of what is produced by BSs of EFL. ENSs comment that they cannot comprehend all the words which are produced by the Bedouins because of the misplacement of stress and the mispronunciation of some sounds. Furthermore, ENSs find it not easy to comprehend the BSs of EFL. On the other hand, ENSs think it is moderate to comprehend BSs of EFL.

In line with the third question 'What are the stress rules of North Sinai Bedouin dialect of Arabic that affect Bedouin speaker's production of EFL?', it is considered as an important question. The study illustrates the features of stress in Bedouin dialect of Arabic in detail. In Bedouin dialect of Arabic, stress is formed by the criterion of quantity. BSs of Arabic keep thelength of long vowels in unstressed positions 
and stress vowels of heavy sequences. In the absence of heavy syllables, stress is formed by the last three or four syllables.

\section{Conclusion}

It has been noticed that English native participants can comprehend more than half of what is said by BSs of EFL and their comprehensibility is about (64\%) to (66\%). ENSs find it moderate for them to communicate with the BSs despite the mispronunciation of some sounds or the misplacement of stress. Furthermore, all of the English listeners think that the pronunciation problems and misplacement of stress are related to the accent or dialect of the Bedouin speakers. BSs of EFL misplace the position of stress when producing English words because of the influence of their Bedouin dialect of Arabic. The study shows that BSs of EFL often misplace the position of stress in some English words that subsequently may interrupt the flow of communication and lead to unintelligibility and incomprehensibility. 


\section{References}

Albini, A., B., \& Becker, M., R. (2014). Perception and Production of English Stress by Brazilian Speakers. Concordia Working Papers in Applied Linguistics, 5.

Clark, J., \& Yallop, C. (2000). An Introduction to Phonetics and Phonology (pp. 340-357, 410-411). Beijing: Foreign Language Teaching and Research Press.

Crystal, D. (2004). The Cambridge Encyclopedia of the English language. Cambridge, Cambridge University Press.

De Jong, R. E. (2000): A grammar of the Bedouin Dialects of the Northern Sinai Littoral. Leiden. Boston. Brill.

El Salman, M., (2016). The Linguistic and Social Aspects of the Bedouin Dialect. Retrieved from http://dx.doi.org/10.7575/aiac.alls.v.7n.4p.20. Vol. 7 No. 4.

El-Hassan, I., M. (2014). Pronunciation Problems: A Case Study of English Language Students at Sudan University of Science and Technology. English Language and Literature Studies; Vol.4. doi:10.5539/ells. v4n4p31, Retrieved from http://dx.doi.org/10.5539/ells.v4n4p31.

Helal, Sh. (2014). Stress in English: Prosodic and Rhythmic Complexity for Arab Learners. Newcastle University. Concordia Working Papers in Applied Linguistics.

Huneety, A., \& Mashaqba, B. (2016). Stress Rules in Loan Words in Bedouin Jordanian Arabic in the North of Jordan: A Metrical Account. Hashemite University. Journal of Theoretical Linguistics, vol. 13, no.3 [cit. 2016-12-19]. 
Retrieved from

http://www.skase.sk/Volumes/JTL33/pdf_doc/01.pdf.ISSN 1336- 782X.

Kreidler, Ch. W. (2002). Describing Spoken English. USA \& Canada, Routledge, New York.

Labov, W., Ash, Sh., \& Boberg, Ch. (2006). The Atlas of North American English: Phonetics, Phonology and Sound Change. New York. Berlin

Ladefoged, P., \& Johnson, K. (2011). A course in Phonetics ( $6^{\text {th }}$ ed.). Boston, MA: Wadsworth.

Mashaqba, B., (2015). The Phonology and Morphology of Wadi Ramm Arabic. Retrievedfrom http://usir.salford.ac.uk/id/eprint/35887/1/anas22thesisviva.

McMahon, A. (2002). An Introduction to English Phonology. Edinburgh, Edinburgh University Press Ltd.

Roach, P. (2009). English Phonetics and Phonology $\left(4^{\text {th }}\right.$ ed.). Cambridge, New York, Melbourne. Cambridge University Press 